\title{
Analysis of a Major Phenolic Glucoside and Biochemistry Compounds from Curculigo Orchioides Gaertn
}

\author{
Thanh Pham*1 ${ }^{1}$ Nu Ngoc Doan Huyen Phan ${ }^{1}$, Van Giang Tran ${ }^{1}$, \\ Thi Quynh Nguyen ${ }^{1}$, Minh Duc Tran², Thanh Hung Nguyen ${ }^{3}$
}

\begin{abstract}
Background: Orcinol- $\beta$-D-glucoside, which is also known as orcinol glucoside, is a major phenolic glucoside compound in the rhizome of the Curculigo orchioides Gaertn. This compound has many medicinal properties such as being antioxidant, immunomodulatory, antiosteoporosis, stress relief, antidepressant, etc.

Methods: Determination of reducing sugar content by Bertrand's method, determination of lipid content by Soxhlet method, determination of vitamin $C$ content by iodine titration, determination of enzyme activity catalase by titration with $\mathrm{KMnO} 4$. Quantification of Orcinol- $\beta$-D-glucoside was conducted by HPLC analysis.

Results: The Orcinol- $\beta$-D-glucoside of $C$. orchioides in Thuy Bang mountain was highest. Besides, the content of reducing sugars, vitamin $\mathrm{C}$, enzyme catalase, and lipids of $C$. orchioides differed significantly among sites. In which, the reducing sugar and vitamin $\mathrm{C}$ of $C$. orchioides in Ngu Binh mountain was highest. Whereas, enzyme catalase was also highest in Thuy Bang mountain. However, the lipid content of $C$. orchioides was also highest in Huong Tho mountain.

Conclusions: The result will contribute to providing the scientific basis for the selection of breeding, planting, development of $C$. orchioides in Thua Thien Hue province, as well as other provinces in Vietnam and opening new research directions for applications in the future.
\end{abstract}

Keywords: Antioxidants, Hypoxidaceae, Medicinal Plants, Vietnam.

\section{Introduction}

Curculigo orchioides Gaertn (C. orchioides) belongs to the family Hypoxidaceae, which is one of the important medicinal plants in Vietnam and is popularly recognized by various names such as Sam cau, Ngai cau, Co noc lan (1-3). It is often used for traditional medicine in China, India and Southeast Asia, including Vietnam. The rhizomes of this plant were used for treatments of impotence, enuresis, cold sperm, back and knee pains, limb numbness, decline in physical strength, diarrhea. They were also used as a potent immunomodulatory and aphrodisiac, etc $(2,4)$. Besides, $C$. orchioides was also used for treatments of leukorrhea, anemia, neurasthenia, diuretics, rheumatism, and movement difficulty in Vietnam $(3,5)$.

There was some previous research on the pharmacological effects of this compound have shown that Orcinol- $\beta$-D-glucoside have antioxidant effects and might be useful to treat skin aging immunomodulatory, antiosteoporosis, anxiolytic effect, antidepressant and it is potential cytotoxic agent 
against gastric, colon and hepatoma carcinoma cell lines (6-14). In Vietnam, the study of Nguyen and Nguyen also showed that the antioxidant ability of pharmaceutical materials was quite high with $66.25 \%$ (1). Additionally, there were also several quantitative studies of phenolic glucoside compounds including Orcinol- $\beta$-D-glucoside but their quantitative methods are different $(15,16)$. In Vietnam, this was a research project to build a qualitative and quantitative method of Orcinol- $\beta$-D-glucoside in rhizomes of $C$. orchioides but its work only evaluated on some samples collected in a limited number of site (17). While the studies on genetic diversity of $C$. orchioides populations from Vietnam in 2018 shows that there were 7 provinces (including Lai Chau, Quang Binh, Quang Tri, Thua Thien Hue, Quang Nam, Kon Tum and Lam Dong) with high different genetic diversity, therein, the populations originate from Thua Thien Hue had the highest genetic identity (0.9407) (18).

Further, some studies on $C$. orchioides focus on breeding by rhizome stem cutting and in vitro in Vietnam $(19,20)$. Thus, researching on Orcinol- $\beta$-D-glucoside and biochemistry compound in the rhizomes of $C$. orchioides in sites of Vietnam is needed.

\section{Materials and Methods Sample Collection}

C. orchioides was collected in 4 sites in Thua Thien Hue province, Vietnam including Phu Bai mountain of Phu Bai town, Huong Tho Mountain of Huong Tra district, Ngu Binh mountain of Hue city, and Thuy Bang Mountain of Huong Thuy district (Fig. 1). In each study locality, we randomly collected 30 trees at a distribution.

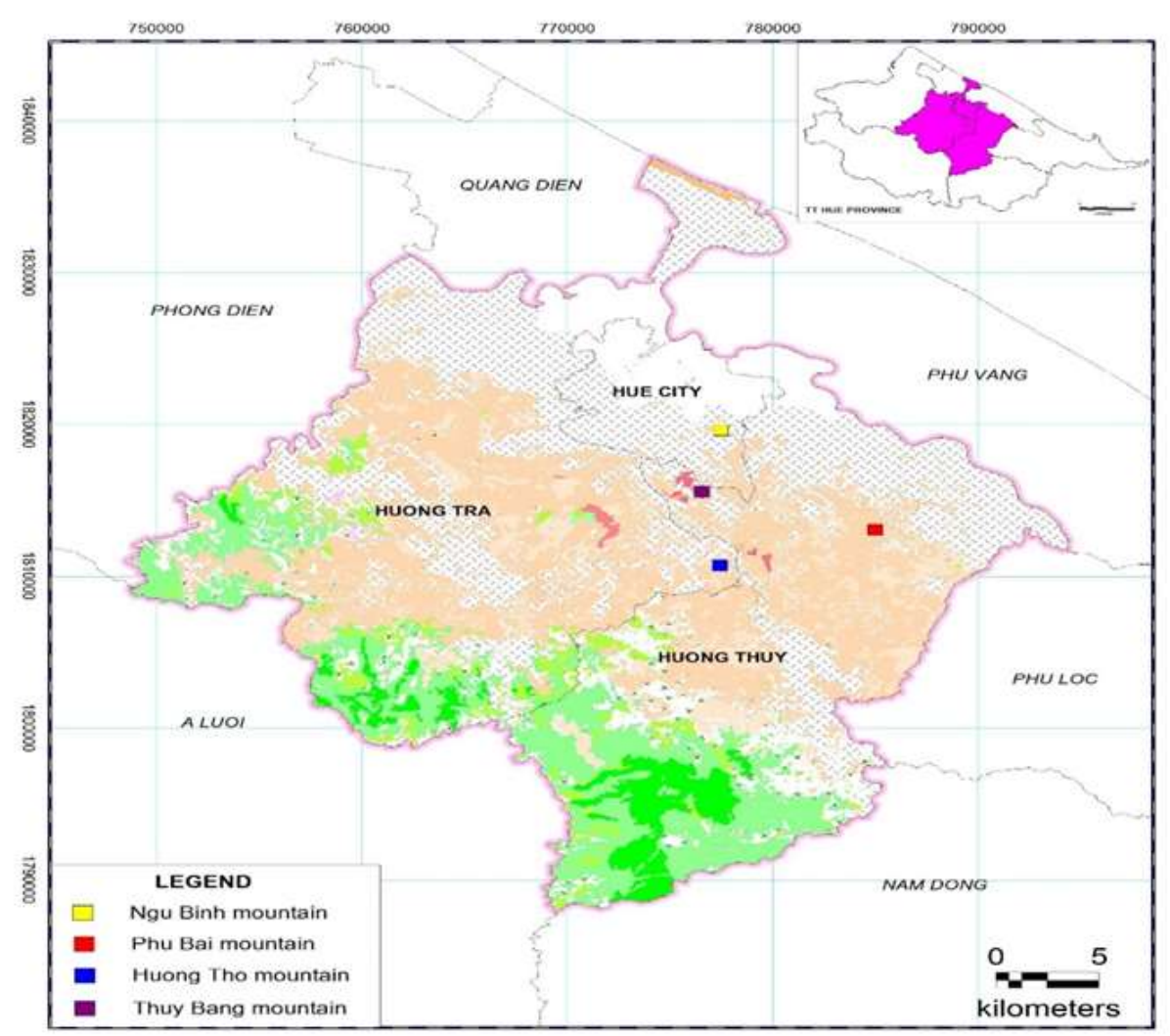

Fig. 1. The sample of Curculigo orchioides in different site of Thua Thien Hue province, Vietnam.

\section{Sample Treatment}

Samples collected from the wild are washed. The secondary roots were removed, using only rhizomes for analysis. Next, the samples are crushed in porcelain mortar with liquid nitrogen and dried at $60{ }^{\circ} \mathrm{C}$ for 48 hours. Finally, the samples were crushed into fine 
powder and put in glass jars and stores in the refrigerator compartment.

\section{Analysis of biochemistry compounds (reducing sugar, lipid, vitamin $C$, iodine titration and enzyme activity catalase) of Curculigo orchioides \\ Determination of reducing sugar content by Bertrand's method (21), determination of lipid content by Soxhlet method, determination of vitamin $\mathrm{C}$ content by iodine titration, determination of enzyme activity catalase by titration with $\mathrm{KMnO} 4$.}

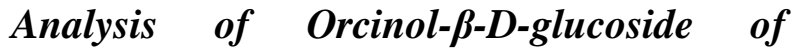 Curculigo orchioides}

One gram of sample was weighed accurately and with $100 \mathrm{~mL}$ solvent into a $300 \mathrm{~mL}$ roundbottomed flask. To investigate the effect of solvents and extraction methods on the results of Orcinol- $\beta$-D-glucoside quantification, we use the formulas in Table 1. Then, the extract was transferred to centrifugal tube and centrifuged (6000 rpm) for $20 \mathrm{~min}$. The solution was filtrated through a $0.45 \mu \mathrm{m}$ cellulose acetate membrane filter before HPLC analysis HPLC Fingerprinting. Using HPLC - LC 20AD (Shimadzu) high performance liquid chromatography system (HPLC InertSustain C18 GL Sciences column). Conditions for running HPLC according to Tu (16). Extracts $(10 \mu 1)$ were analyzed using a phase device: ACN: H2O (10:90, v/v) with HPLC column (250 x 4.6mm; $5 \mu \mathrm{m})$, helium carrier gas flow at $0.5 \mathrm{ml}-1$. UV-VIS detector was detected wavelength of $220 \mathrm{~nm}$. Using standard substances with Orcinol- $\beta$-D-glucoside of Solarbio (China) has purity of over $98 \%$.

Table 1. Formulas used to investigate the effect of solvents and extraction methods on the results of Orcinol- $\beta$-D-glucoside of quantification.

\begin{tabular}{cccc}
\hline STT & Treatment & Solvent & Extraction method \\
\hline $\mathbf{1}$ & CT-1 & Methanol 100\% & Soxhlet in 2 hours \\
\hline $\mathbf{2}$ & CT-2 & Methanol $70 \%$ & Soxhlet in 2 hours \\
\hline $\mathbf{3}$ & CT-3 & Methanol 16\% & Soxhlet in 2 hours \\
\hline $\mathbf{4}$ & CT-4(Control) & Dissolve 1mg of Orcinol- $\beta$-D-glucoside standard into $1 \mathrm{ml}$ methanol $100 \%$ \\
\hline
\end{tabular}

\section{Data processing}

The collected data is processed on a computer using the SPSS 20 software.

\section{Results}

\section{Effect of solvent and extraction method on} quantitative results of Orcinol- $\beta-D$ glucoside in HPLC fingerprinting

The results showed that the retention time of Orcinol- $\beta$-D-glucoside in all treatments around the 20th minute, indicating that this compound is present in 4 samples (Table 2, Fig. 3). The results of quantitative analysis of Orcinol- $\beta$-D-glucoside in the formulas showed that this substance content was different when using different extraction and solvent methods with statistical significance $(\mathrm{p}<0.0001, \mathrm{~F}=$ $3.415 \mathrm{E}+11, \mathrm{df}=4)$. The Tukey's test indicated that the CT 1 was significantly highest compared with the other treatment (CT-2, CT3), except CT4 (control). Therefore, we use $100 \%$ methanol solvent to extract Orcinol- $\beta$ D-glucoside from the sample base (Table 2).

\section{Constructing a calibration curve and linear regression equation}

The linear dependence of the chromatographic peak area on the concentration of Orcinol- $\beta$-Dglucoside are shown at Fig. 3. There is a close correlation between peak area and concentration of Orcinol- $\beta$-D-glucoside. The coefficient of determination $\mathrm{R}^{2}=0.99995$ is content with condition $0.99 \leq \mathrm{R}^{2} \leq 1$ and the bias $\Delta$ does not exceed $\pm 15 \%$ for all concentrations being used to build the standard line. Therefore, the standard curve that was built is acceptable. 
Table 2. Effect of solvent and extraction methods on quantitative results of Orcinol- $\beta$-D-glucoside in HPLC Fingerprinting.

\begin{tabular}{ccccc}
\hline Order & Treatment & Peak area $(\mathbf{m A U} * \mathbf{s})$ & $\begin{array}{c}\text { Retention time (r.t) } \\
(\mathbf{m i n})\end{array}$ & Concentration $(\mathbf{m g} / \mathbf{m l})$ \\
\hline $\mathbf{1}$ & $\mathbf{C T}-\mathbf{1}$ & $\mathbf{5 4 4 6 3 5} \pm \mathbf{3 4 . 2 1 c}$ & $20.390 \pm 0.0115$ & $\mathbf{0 . 0 2 0 0} \pm \mathbf{0 . 0 0 c}$ \\
$\mathbf{3}$ & $\mathbf{C T}-\mathbf{2}$ & $225021 \pm 10.15 \mathrm{a}$ & $20.386 \pm 0.0003$ & $0.0083 \pm 0.00 \mathrm{a}$ \\
$\mathbf{4}$ & $\mathbf{C T}-\mathbf{3}$ & $229150 \pm 19.50 \mathrm{~b}$ & $20.475 \pm 0.00145$ & $0.0084 \pm 0.00 \mathrm{~b}$ \\
$\mathbf{5}$ & $\mathbf{C T}-\mathbf{4}$ & $27228355 \pm 19.16 \mathrm{~d}$ & $20.419 \pm 0.00176$ & $1 \pm 0.00 \mathrm{e}$ \\
$\mathbf{F}$ & & & $\mathbf{3 . 4 1 5 E + 1 1}$ & \\
$\boldsymbol{P}$ & & & $<0.0001$ & \\
\hline
\end{tabular}

Lower-case letters in a cell show the results of significant differences between treatments using Tukey's multiple range test $(p<0.05)$. The values represent the mean $( \pm$ SE) of three independent experiments. The highest statistically significant mean value was bold. The signal E+11 means $10^{11}$.

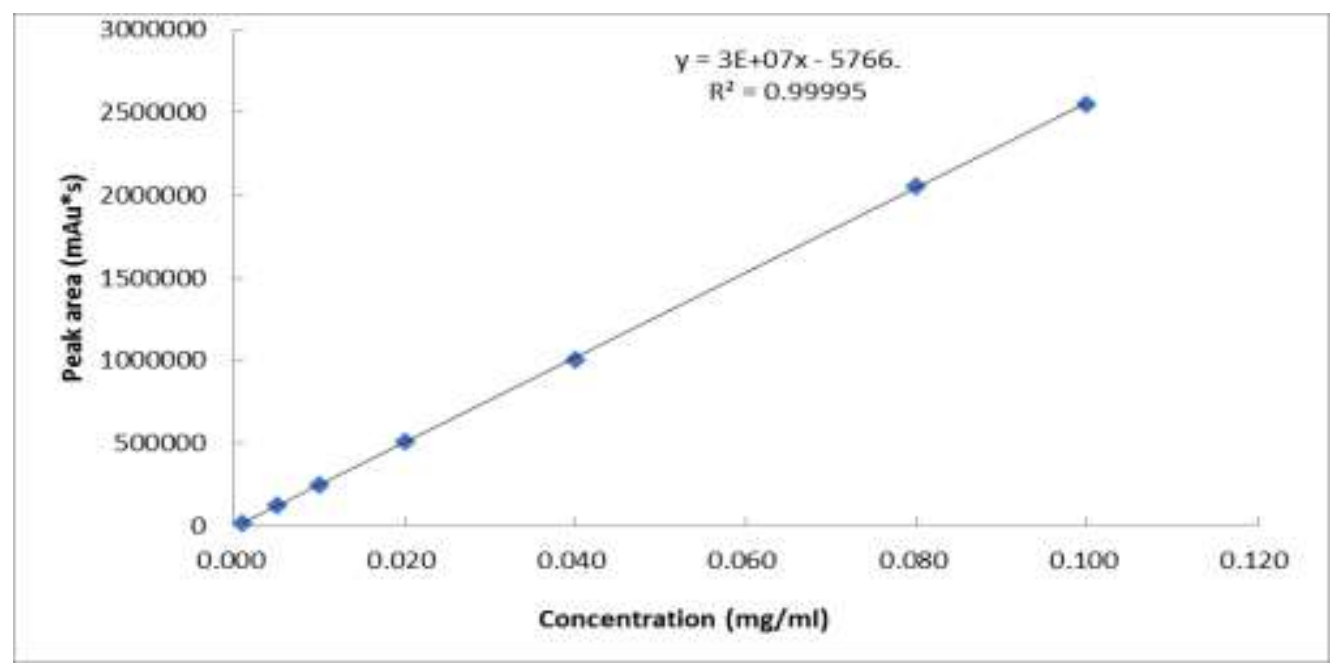

Fig. 2. The calibration curve of Orcinol - $\beta$ - D - glucoside in HPLC fingerprinting: The signal E+7 means $10^{7}$.
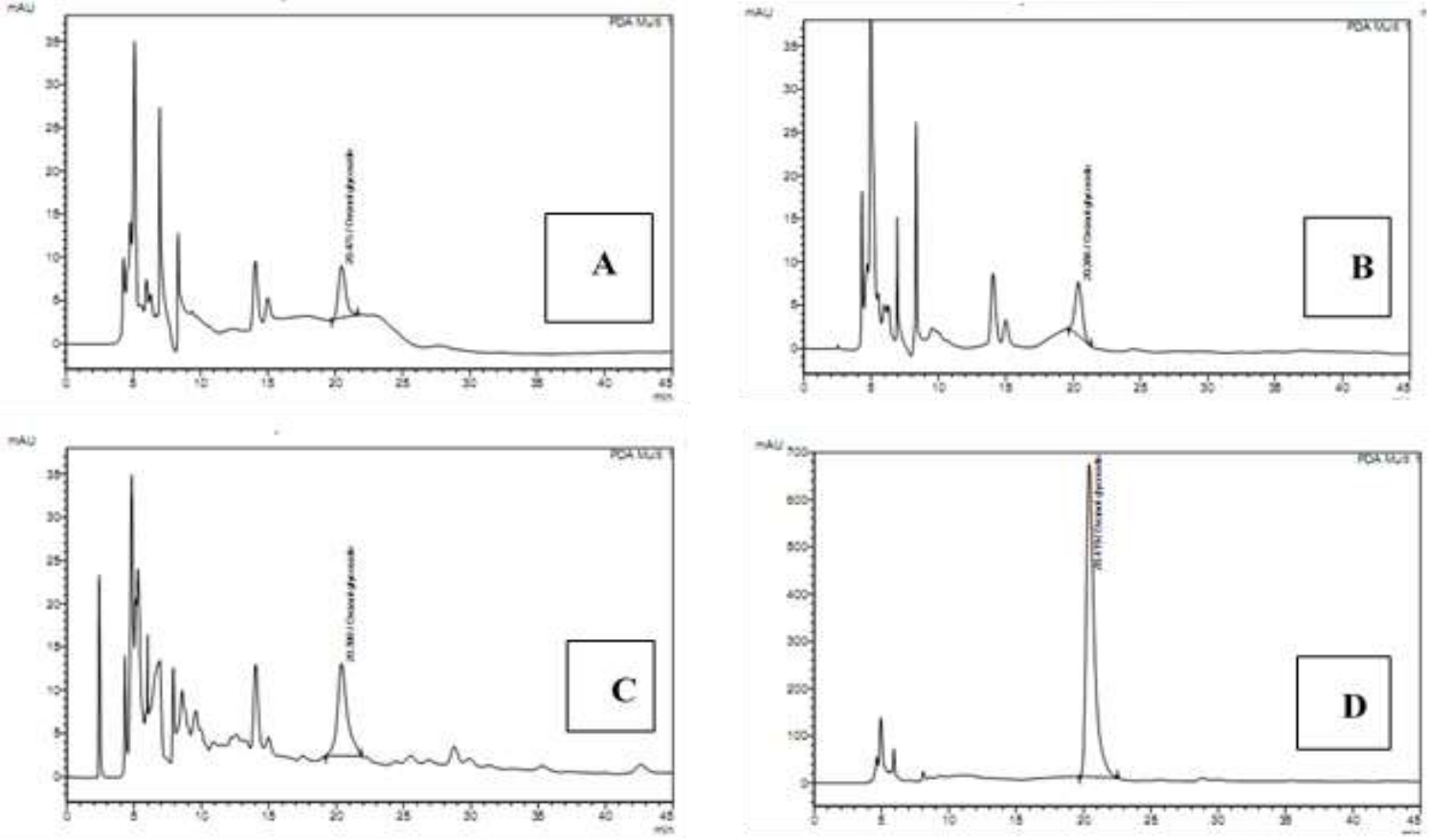

Fig. 3. HPLC chromatogram of the dry rhizome of Curculigo orchioides Gaertn. extract visualized by A) CT-3, B) CT2, C) CT-1, and D) CT-4. The vertical axis is intensity (mAU), the horizontal axis is retention time (min). The retention time of Orcinol- $\beta$-D-glucoside compound in 4 formulas are all around the 20th minute. 
Effect different site on Orcinol- $\beta$-D-glucoside content of $C$. orchioides

The results of quantitative analysis of Orcinol$\beta$-D-glucoside in the rhizome samples of $C$. orchioides showed that the content of this substance has a difference between the distribution site with statistical significance $(\mathrm{p}<0.0001, \mathrm{~F}=8529.239, \mathrm{df}=10)$. Using
Tukey's test shown that the content of Orcinol$\beta$-D-glucoside of $C$. orchioides distributed in Thuy Bang - Thua Thien Hue was highest (Table 3, Fig. 4). The results of quantitative analysis by HPLC in the rhizome samples of $C$. orchioides in sites showed that the Orcinol$\beta$-D-glucoside content ranges from $1.27 \pm 0.0020$ to $9.16 \pm 0.0189 \mathrm{mg} / \mathrm{g}$.

Table 3. Content of Orcinol- $\beta$-D-glucoside in C. orchioides Gaertn in different sites Thua Thien Hue province, Vietnam.

\begin{tabular}{cc}
\hline Locality & Content $(\mathbf{m g} / \mathbf{g}$ dried) \\
\hline Ngu Binh mountain & $3.66 \pm 0.0038 \mathrm{c}$ \\
Phu Bai mountain & $1.35 \pm 0.0056 \mathrm{a}$ \\
Huong Tho mountain & $6.41 \pm 0.0422 \mathrm{~d}$ \\
Thuy Bang mountain & $\mathbf{9 . 1 6 \pm 0 . 0 1 8 9 \mathrm { e }}$ \\
$\mathbf{F}$ & $\mathbf{8 5 2 9 . 2 3 9}$ \\
$\boldsymbol{P}$ & $<0.0001$ \\
\hline
\end{tabular}

Lower-case letters in a cell show the results of significant differences between treatments using Tukey's multiple range test $(p<0.05)$. The same letters within each column indicates no statistically significant differences. The values represent the mean $( \pm \mathrm{SE})$ of three independent experiments. The highest statistically significant mean value was bold.
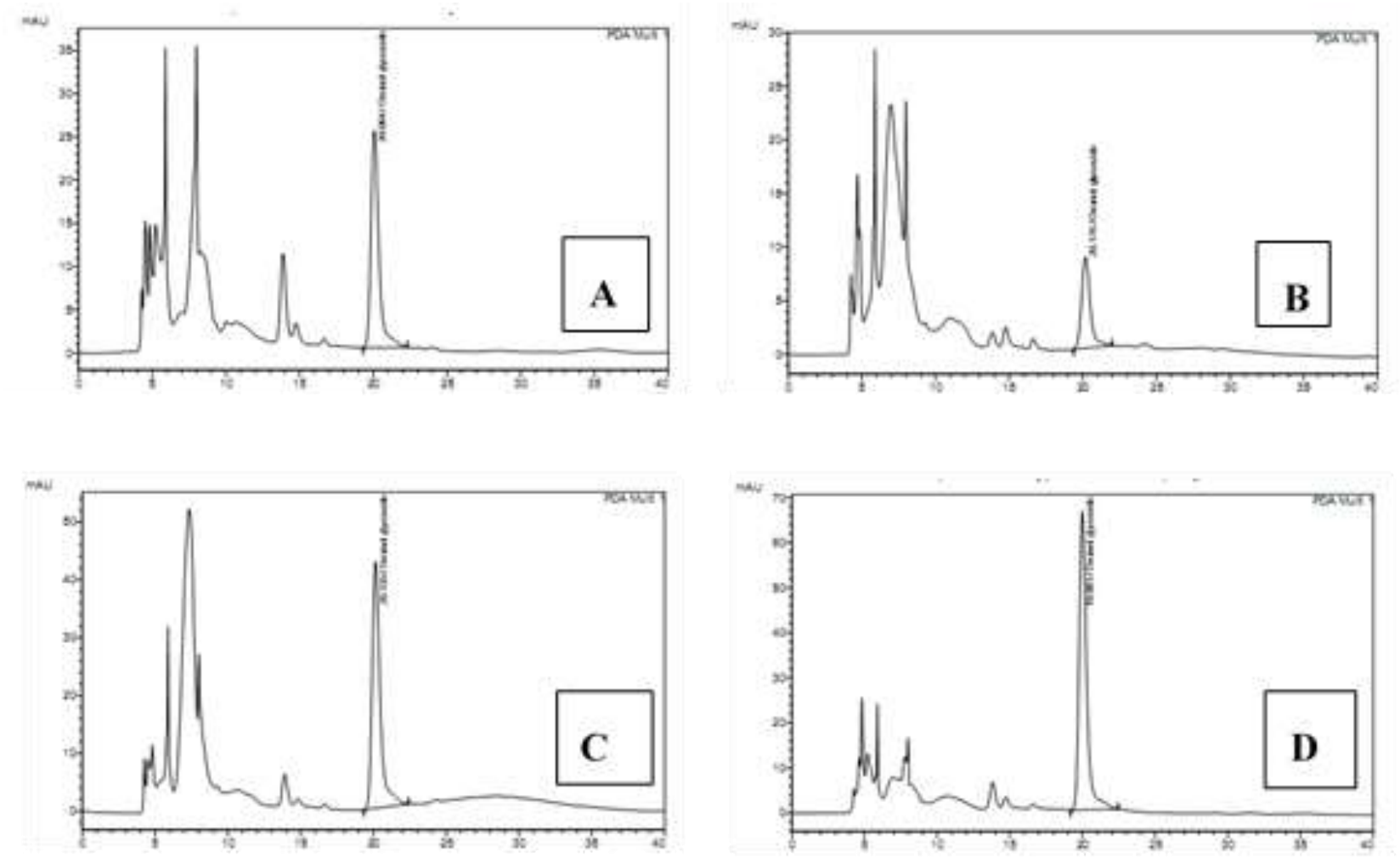

Fig. 4. HPLC Fingerprint of 04 samples by A) Ngu Binh mountain (Hue city), B) Phu Bai mountain (Phu Bai town), C) Huong Tho mountain (Huong Tra district), D) Thuy Bang mountain (Huong Thuy district). The vertical axis is intensity $(\mathrm{mAU})$, the horizontal axis is retention time (min). The retention time of Orcinol- $\beta$-D-glucoside compound in 4 samples are all around the 20th minute. 
Analysis of biochemistry compounds of Curculigo orchioides

The results of quantitative determination of reducing sugars, lipids, vitamin $\mathrm{C}$, and catalase activity in rhizomes of $C$. orchioides in the sites were statistically significantly different (Table 2). Using Tukey test shows that the reducing sugar and vitamin $\mathrm{C}$ of $\mathrm{C}$. orchioides distributed in Ngu Binh mountain was highest, while the highest lipid of $C$. orchiodes was Huong Tho mountain. The activity of the catalase enzyme of $C$. orchioides distributed in Thuy Bang mountain was highest (Table 4). Quantitative results of some biochemical parameters in rhizomes of $C$. orchioides showed a difference between sites.

Table 4. Biochemistry compounds of $C$. orchioides Gaertn in different sites of Thua Thien Hue province, Vietnam.

\begin{tabular}{ccccc}
\hline & \multicolumn{4}{c}{ Average content } \\
\cline { 2 - 5 } Sites & Reducing sugar (\%) & Lipid (\%) & Catalase (U/g) & Vitamin C (\%) \\
\hline Ngu Binh mountain & $\mathbf{4 . 6 5} \pm \mathbf{0 . 0 3 d}$ & $2.05 \pm 0.04 \mathrm{a}$ & $168.06 \pm 1.39 \mathrm{c}$ & $\mathbf{3 . 7 4} \pm \mathbf{0 . 0 2 3 c}$ \\
Thuy Bang mountain & $4.35 \pm 0.03 \mathrm{c}$ & $2.97 \pm 0.033 \mathrm{c}$ & $\mathbf{1 7 2 . 5 5} \pm \mathbf{2 . 0 0 c}$ & $2.42 \pm 0.13 \mathrm{a}$ \\
Huong Tho mountain & $3.88 \pm 0.04 \mathrm{~b}$ & $\mathbf{3 . 0 5} \pm \mathbf{0 . 0 2 d}$ & $152.22 \pm 1.70 \mathrm{~b}$ & $3.30 \pm 0.13 \mathrm{ab}$ \\
Phu Bai mountain & $2.85 \pm 0.03 \mathrm{a}$ & $2.53 \pm 0.02 \mathrm{~b}$ & $112.47 \pm 1.46 \mathrm{a}$ & $2.35 \pm 0.07 \mathrm{a}$ \\
F & 278.70 & 419.10 & 272.01 & 213.68 \\
p & $<0.0001$ & $<0.0001$ & $<0.0001$ & $<0.0001$ \\
\hline
\end{tabular}

\section{Discussion}

In our study, the results of quantitative analysis by HPLC in the rhizome samples of $C$. orchioides in four sites showed that the Orcinol$\beta$-D-glucoside content ranges from 1.27 to 9.16 $\mathrm{mg} / \mathrm{g}$. This result was higher than that of He et al (16), in which Orcinol- $\beta$-D-glucoside content only ranges from 0.333 to $2.854 \mathrm{mg} / \mathrm{g}$.

When using $100 \%$ methanol solvent and Soxhlet extraction method, Orcinol- $\beta$-Dglucoside quantitative result was higher than when using $70 \%$ ethanol solvent and extraction method under reduced pressure at $60{ }^{\circ} \mathrm{C}$.

This result was similarly to the study of Bian et al. in which the Orcinol- $\beta$-D-glucoside content ranges from 1.43 to $11.58 \mathrm{mg} / \mathrm{g}$ (15). The samples collected at Thuy Bang mountain $(9.16 \pm 0.0189 \mathrm{mg} / \mathrm{g})$ were only lower than Yulin - Guangxi (11.58 mg/g) but higher than the 9 remaining sites in China. In comparing this result with the research results in Vietnam, Orcinol- $\beta$-D-glucoside content in $C$. orchioides sample distributed at Thuy Bang mountain was highest (16). This proves that, when using $100 \%$ methanol as a solvent, it will yield higher quantitative results than $60 \%$ ethanol. From this, we have found that among the sites in Vietnam, C. orchioides distribution in Thuy
Bang mountain should be selected for planting and developing and for constructing a product branding later.

Around the world, rhizomes of $C$. orchioides distribution site was used in making supplements in various types such as tea, powder, extract, and tablet tonic. Besides, the rhizomes extract of $C$. orchioides distribution was also being used as the main ingredient in the production of cosmetics for women thanks to its anti-inflammatory properties, wound healing, stimulating cell regeneration.

In particular, the reducing sugar content (glucose) in the experimental samples is higher than the results in Joy's study (22). Lipid content in the experimental samples is similar to the results of Joy and Arinathan et al. In particular, the lipid content in the sample of Cucumber originating in Ngu Binh is higher than that of two sites in India (21). The content of vitamin $\mathrm{C}$ is much different among sites and lower than the research results of Arinathan et al. (23). The enzyme catalase activity in $C$. orchioides samples from different origins is very high, proving that the antioxidant capacity of medicinal herbs is very good.

According to Pham et al. when studying the 
distribution of $C$. orchioides in Thua Thien Hue, the condition where the distribution of the species is under pine forest with canopy coverage of $0-50 \%$, distributed in height is from $30-130 \mathrm{~m}$ above water level, the slope is up to $30^{\circ} \mathrm{C}$, but it is concentrated in the height of $30-60 \mathrm{~m}$ and canopy cover is from $0-5 \%$, temperature is $24-25.2^{\circ} \mathrm{C}$, average rainfall year $2,600-2,800 \mathrm{~mm}$ and humidity $83-84 \%$. In addition, the soil in the natural distribution of $C$. orchioides is usually brown to reddish brown or pale yellow Leptosols, or Acrisols are gray to grayish yellow, soil mixed with gravel and

\section{References}

1. Nguyen TB. Handbook to reference and identification of the families of Angiospermae plants in Vietnam. Agricultural publisher. 1997;68-69.

2. Pham HH. Plants in Vietnam. Young publishers, Viet Nam. 2000; vol 3:502-503.

3. Do TL. Vietnamese Medicinal Plants and Remedies. $8^{\text {th }}$ ed. Ha Noi Medicine Publishing House, Viet Nam. 2007;1274.

4. Nie Y, Dong X, He Y, Yuan T, Han T, Rahman K., Luping Q, Zhang Q. Medicinal plants of genus Curculigo: traditional uses and a phytochemical and ethnopharmacological review. J Ethnopharm. 2013;147(3), 547-563. 7.

5. Pham T, Tran MD, Nguyen HS. Investigating the distribution and planting test model of outside the ecological distribution of Curculigo orchioides in Thua Thien - Hue province. Journal of Agriculture and Rural Development. 2018; 22(2):130-135.

6. Pham T, Tran MD, Nguyen T, Pham QC, Nguyen QC. Rapid vegetative propagation of Curculigo orchioides Gaertn. using rhizome cutting, endangered medicinal herb. Int J Agric Innov and Res. 2018; 7:156-158.

7. Liu $\mathrm{X}, \mathrm{Hu} \mathrm{Y}$, Wei D. Optimization of enzyme-based ultrasonic/microwave-assisted extraction and evaluation of antioxidant activity of orcinol glucoside from the rhizomes of Curculigo orchioides Gaertn. Med Chem Res. 2013;23:2360-2367.

8. Lee SY, Kim MR, Choi HS, Moon HI, Chung $\mathrm{JH}$, Lee DG, et al. The effect of curculigoside on the expression of matrix metalloproteinase- 1 in surface soil often eroded, gravel from 20 - 70\%; rotten floor mats are very thin and usually only about $0.1-1.5 \mathrm{~cm}$. In particular, soil moisture in the surface layer is from $0-30 \mathrm{~cm}$ quite high, ranging from $30-40 \%$ (5).

\section{Acknowledgements}

This work was supported by Hue University Strong Research Teams (Conservation and Development of Medicinal Plant and NonTimber Forest Products (NTFPs) Resources)03 Le Loi str., Hue city, Vietnam.

cultured human skin fibroblasts. Arch Pharm Res. 2009;32(10):1433-9.

9. Bafna AR, Mishra SH. Immunostimulatory effect of methanol extract of Curculigo orchioides immunosuppressed mice. J Ethnopharmacol. 2006;104(1-2):1-4.

10. Lakshmi V, Pandey K, Puri A, Saxena RP, Saxena KC. Immunostimulant principles from Curculigo orchioides. J Ethnopharmacol. 2003;89:181-4.

11. Cao DP, Zheng YN, Han T, Qin P. Advances in research on chemical constituents and bioactivities of plants of Curculigo. Pharm Care Res. 2008;8(1):59-62.

12. Wu Q, Fu DX, Hou AJ, Lei GQ, Liu ZJ, Chen $\mathrm{JK}$, et al. Antioxidative phenols and phenolic glycosides from Curculigo orchioides. Chemical and pharmaceutical Bulletin. 2005;53(8):10651067.

13. Ge JF, Gao WC, Cheng WM, Lu WL, Tang $\mathrm{J}$, Peng L, et al. Orcinol glucoside produces antidepressant effects by blocking the behavioural and neuronal deficits caused by chronic stress. European Neuropsychopharmacology. 2014;24(1):172-180.

14. Chauhan NS, Dixit VK. Phcog mag.: Research Article Antihyperglycemic activity of the ethanolic extract of Curculigo orchioides Gaertn. Phcog Mag., 2007;3(12), 237.

15. Bian Q, Yang H, Chan C, Jin D, Mok DK, Chen S. Fingerprint Analysis and Simultaneous Determination of Phenolic Compounds in Extracts of Curculiginis Rhizoma by HPLC- 
Diode Array Detector. Chem Pharm Bull (Tokyo). 2013;61(8):802-808.

16. He Y, Dong X, Jia X, Li M, Yuan T, Xu H, et al. Qualitative and quantitative analysis on chemical constituents from Curculigo orchioides using ultra high performance liquid chromatography coupled with electrospray ionization quadrupole time-of-flight tandem mass spectrometry. J Pharm Biomed Anal. 2015;102:236-45.

17. Wang X, Li G, Li P, Huang L, Huang J, Zhai H. Anxiolytic effects of orcinol glucoside and orcinol monohydrate in mice. Pharm Biol. 2015;53(6):876-81.

18. Hoang TQ, Bui LTN, Tran MD, Tran VG, Pham T. Study on genetic diversity of Curculigo orchioides Gaertn populations from Viet Nam, an endangered medicinal herb. Plant Cell Biotechnology and Molecular Biology. 2018;19(7\&8):293-301.
19. Pham T, Hoang TT, Tran MD. Effect of different tissues and growth hormones on the in vitro propagation from Curculigo orchioides Gaertn., an endangered medicinal Herb in Vietnam. Res J of Biotechnol. 2019;14(6):80-87. 20. Ramchandani D, Ganeshpurkar A, Bansal D, Karchuli MS, Dubey N. Protective effect of Curculigo orchioides extract on cyclophosphamide-induced neurotoxicity in murine model. Toxicol Int. 2014;21(3):232-235.

21. Bertrand G. Le dosage de sucres reducteurs. Bull Soc Chim. 1906;35:1285-1299.

22. Joy PP. Agrotechnological practices for quality crude drug production in Nillappana (Curculigo orchioides Gaertn.). 2003.

23. Arinathan V, Mohan VR, Maruthupandian A. Nutritionnal and anti-nutritional attributes of some under-utilized tubers. Tropical and Subtropical Agroecosystem. 2009;10(2):273278. 